\title{
Nursing Personnel Perception toward Nursing Shortages Factors and its Effect on Their Work at Benha University Hospital
}

\author{
Magda Ramdan AbdElhamed*, Mona MostafaaShazly, Fawzia**, Farouk Kamel* \\ *NursingAdministration, Faculty of Nursing, Benha University \\ **Nursing Administration, Faculty of Nursing, Ain Shams University.
}

\begin{abstract}
Nursing shortage is one of the most significant barriers of quality of nursing care and patient outcome. Aim: The study aimed to identify nursing personnel perception toward nursing shortage factors and its effect on their work at Benha University Hospitals. Design: Descriptive correlation research design. Setting: The study was conducted at Benha University Hospital. Subjects: Convenient sample consisted of 50 head nurses and 110 staff nurses. Tools: Data of this study were collected by using: (1) Nursing shortage factors questionnaire (2) Strategies for solving nursing shortage questionnaire. The results: The findings of the study showed that; most factors of nursing shortage are related to work overload, inadequate salary and incentives and unsafe work environment. The most study sample agreed on the nursing shortage leads to increase job stressor and low level of productivity. In addition to most study sample agreed on the most strategies to manage the problem of nursing shortage were related to improve nursing image and activate the role of the union. The study concluded: Most studied sample agreed on nursing shortage factors effect on nursing work. The study recommended: that hospital administrators and regulators should take action to ensure that an adequate nursing staff is available to achieve quality nursing care.
\end{abstract}

Key words: Factors affecting, nursing shortage and staff nurses

numbers and qualification given to

\section{Introduction}

Nurses are the main source of care during the most vulnerable times in their lives. They have broad and significant role in impacting the quality and effectiveness of health care delivery which is provided on 24 hours basis each day of the year. Furthermore, the ability of health care delivery system to respond to rapidly evolving health care will depend on the professional nurses, so the shortage in such category could be serious problem (Rashdan, 2007\&Tomey, 2013).

Nursing shortage as a condition in which delicate balance of nurse supply and nurse demand is not at equilibrium. A nursing shortage is not just a matter of understating. Understating can occur in conditions of shortage, equilibrium, or surplus. Nurses or the public may believe there is a shortage based on a variety of 
factors. Depending on local factors such as tight budgets or poor working conditions, increased workload, dissatisfied nurses and tendency to leave the services. Experts generally use indicators such as employer reports, vacancy rates, turnover, recruitment difficulty, staffing levels, Registered nurse (RN )supply per population, or forecasting models to determine a nursing shortage (Buerhaus, Auerbach \& Staiger, $(2009$ \& Diane et al., 2015).

Nursing shortage is considered as a major cause that affects the nurses' productivity, efficiency, effectiveness, and competency. Nurses will becomes more likely to be dissatisfied with their job. Nursing shortage also affects negatively on patient safety and outcome. These lead to increase mortality rates, accident rates, patient injuries, and cross infection rates (Needleman and Beurau, 2009\&Ageiz, 2012).

Based on nursing shortage statistics, there is an urgent need to protect and support this profession. The shortage is getting critical that hospitals find themselves competing for nurses by offering the best benefit plans and the highest pay. Major strategies to manage nursing shortage include; improving workforce planning, incorporation of the characteristics of magnet hospital for attracting and retaining nurses, improving nursing recruitment, retaining nursing staff and improving the image of nursing as a profession (Kuhar et al., 2009).

Additionally (Park \& Jones, 2015) list some strategies to retain new graduates and experienced nurses includes: positive organizational culture; values driven, culture safety, physician-nurse collaborative partnership, creation of community culture, social supports, support services(discussion groups and social networking opportunities) compensation/financial incentives; competitive salaries, financial support associated with credentialing and professional development opportunities, flexibility in work opportunities: flexible hours/schedules, fixed shifts, weekend options. Part-time pay with bonus hours, bonus pay, bonus pay for recruitment of nurses, child/elder care.

\section{Significant of the study:}

Nurses are the heart and backbone of all hospital facilities and the cornerstone of the health care in Egypt. The total number of nurses in Egypt is estimated to be 207.000 nurses with only 56.000 of them members of the syndicate and enjoying its privileges. The majorities of them are marginalized and can not acquire the basic rights. The ministry of health estimates that Egypt suffers from a shortage of 44.000 nurses at all levels. This shortage effect on the nursing personnel works through reducing health work force availability and performance and requires innovative solution by the offering the best benefits plans and the highest pay. So this study conducted to identify nursing personnel perception toward nursing shortage factors and its effect on their work.

\section{Aim of the study:}

This study aims to identify nursing personnel perception toward Nursing Shortages factors and its effect on work at Benha University Hospitals.

\section{Research Questions} factors?

1-What are the nurses shortages

2-What is the effect of nursing shortages on nursing work?

3-What the best strategies for solving nursing shortages? 


\section{Subjects \& methods:}

Design:A descriptive design was utilized in conduct the study

Setting:The study was carried out at Benha University Hospital at Alkaloubia Government, in the following units. Surgical units male \& female, and Medical units $1,2,3,4,5$ and 6 .

Subjects: A convenient sample of all available head nurses and staff nurses at the time of the study

Tool of data collection:
Twoinstrument was used for data
collection

1)Factors nursing shortage questionnaire: It was adopted from Buerhaus et al., (2005), Abd Allah, (2010) and Gab Allah, (2012) to assess nursing personnel perception toward nursing shortages factors and its effect on their work at Benha University Hospital. It consists of three parts:

Part I:this part aimed to collecting data related to socio -demographic characteristics of study sample such as (age, gender, years of experience, material status)

Part II: this part intended to identify nursing shortage factors (personal, social, educational and organizational factors) it was consisted of 24 questions divided into 4 main categories.

PartIII: this part intended to identify effect of nursing shortage on their work. It consisted of 14 questions, divided into two categories:

2) Strategies for solving nursing shortage questionnaire:- It contain 29 items to determine different strategies for solving nursing shortages divided into three categories

\section{Reliability of instrument}

Internal consistency for the interviewing questionnaire was reliability of data collection first tool $=0.76$ in study subject and second tool reliability of strategy $\alpha=0.72$

3- Pilot study: A Pilot study was conducted at October 2015 on about $10 \%$ of total sample 10 nurses and 5 head nurses. The aim was to examine the sequence of items, feasibility, practicability and applicability of the tool, clarity of the language and for estimating the time needed to fill it out. The time required to fill the questionnaire was from (10-15) minutes. The tool was finalized based on the result of the pilot study. The pilot studies were included in the sample..

4-Procedure: Each nurse \& head nurses were interviewed individually after explaining the purpose of the study \& getting agreement of staff nurses \& head nurses to participate in the research.

- Data has been collected from staff nurses \& head nurses at Benha University Hospital

- The data were collected three days of week during the morning shift. The work was done between 10:00 am to 12:00 pm. The field work lasted for two months from the beginning from November 2015 to December 2015 The average number of nurses filled the questionnaire sheets were between 4-5 nurses per day.

- The time needed to complete questionnaire sheet (10-15) minute.

\section{Ethical consideration:}

The study will be conducted with careful attention to ethical st\&ards of research \& rights of the participants: 
The study protocol was approved by the research and Ethics committee at the Faculty of Nursing University. Oral informed consents were obtained from the participants. They were informed about their rights to refuse or withdraw from the study with no consequences. They were reassured about the anonymity and confidentiality of the information collected, and would be used only for the purpose of scientific research.

\section{Statistical design}

Data entry and statistical analysis were done by using SPSS version 20.0 statistical software package. Data were presented using. descriptive statistics in the form of frequencies percentage for qualitative variables. Qualitative variables were compared using chi-square test. Pearson correlation was used for assessment of the inter-relationships among quantitative variables. Fischer exact test for $2 \times 2$ tables when expected cell count of more than $25 \%$ of cases was less than 5. Multiple linear regression analysis was used after testing for normality, and analysis of variance for the full regression models were done. Statistical significance was considered at $\mathrm{p}$-value $<0.05$.

\section{Results}

Table (1): Shows percentages distribution of studied group regarding their demographic characteristic. The result revealed that $(62 \% \& 47.3 \%)$ of head nurse and nurses were in the age $30-40$ respectively. In relation to gender, $(86 \%$ \& $60.9 \%$ ) of head nurse $\&$ nurses were female.
All of the head nurse $(100 \%)$ has bachelor degree while $(72.7 \%)$ of nurses have diploma in nursing. The majority $(92 \% \& 87.3 \%)$ of head nurse \& nurse were married respectively. Regarding to years of experience $(70 \% \& 34.5 \%)$ of head nurse \& nurses has more than 15 years of experience. On the other hand there was a statistical significant difference between studied group and their demographic characteristic

Table (2): Shows percentage distribution studied group regarding total agreement of nursing shortage. The result revealed that there was a highly statistical significant difference between studied group regarding their agreement on organizational factors and social factors $(\mathrm{P}<0.001)$. Also there was a statistical significant difference between studied group their agreement about total nursing shortage factors $(\mathrm{P}<0.05)$.

Table (3) display best fitting multiple linear regression models explaining of the effect nursing shortage of nurses work. This table shows the nursing shortage factors were significant predictors on nurse's work.

Table (4): Shows percentage distribution of the strategy to manage nursing shortage problem through ministry of health as reported by studied group agreement all items regarding community outreach programs for improving nursing image and honoring the ideal nurse $(100 \%)$ respectively. On the other hand the result demonstrated that there wasn't a statistical significant difference between studied group. 


\section{Table (1): Distribution of study sample regarding their demographic} characteristic no $=(\mathbf{1 6 0})$

\begin{tabular}{|l|c|c|c|c|}
\hline \multirow{2}{*}{ Socio demographic characteristics } & \multicolumn{2}{|c|}{$\begin{array}{c}\text { Head nurses } \\
\text { (N=50) }\end{array}$} & \multicolumn{3}{c|}{$\begin{array}{c}\text { Nurses } \\
\text { (N=110) }\end{array}$} \\
\cline { 2 - 5 } & No. & \% & No. & \% \\
\hline Age & & & & \\
$<20$ & 2 & 4 & 4 & 3.6 \\
$>20-25$ & 5 & 10 & 19 & 17.3 \\
$>25-30$ & 12 & 24 & 20 & 18.2 \\
$>30-40$ & 31 & 62 & 52 & 47.3 \\
$>40$ & 0 & 0 & 15 & 13.6 \\
\hline Gender & & & & \\
Male & 7 & 14 & 43 & 39.1 \\
Female & 43 & 86 & 67 & 60.9 \\
\hline Nursing qualification: & & & & \\
Bachelor degree in nursing & 50 & 100 & 0 & 0 \\
Nursing school diploma & 0 & 0 & 30 & 27.3 \\
Master degree in nursing & 0 & 0 & 0 & 0 \\
Doctor degree in nursing & 0 & 0 & 0 & 0 \\
Associated degree in nursing & 0 & 0 & 80 & 72.7 \\
\hline Marital status & & & & \\
Single & 1 & 2 & 13 & 11.8 \\
Married & 46 & 92 & 96 & 87.3 \\
Divorced & 3 & 6 & 1 & 0.9 \\
\hline Years of experience & & & & \\
$<5$ & 7 & 14 & 19 & 17.3 \\
$>5$ - 10 & 8 & 16 & 20 & 18.2 \\
$>10-15$ & 0 & 0 & 33 & 30 \\
$>15$ & 35 & 70 & 38 & 34.5 \\
\hline
\end{tabular}

Table (2): Agreement of nursing staff on shortage factors. No (160)

\begin{tabular}{|c|c|c|c|c|c|c|c|c|c|c|c|c|c|c|}
\hline \multirow{3}{*}{$\begin{array}{l}\quad \text { Total factor } \\
\\
\text { Nursing } \\
\text { shortage } \\
\text { factors }\end{array}$} & \multicolumn{6}{|c|}{$\begin{array}{c}\text { Head nurses } \\
(\mathrm{N}=50)\end{array}$} & \multicolumn{6}{|c|}{$\begin{array}{l}\text { Nurses } \\
(\mathrm{N}=110)\end{array}$} & \multirow[t]{3}{*}{$\chi^{2}$} & \multirow{3}{*}{$\begin{array}{c}\mathbf{P} \\
\text { value }\end{array}$} \\
\hline & \multicolumn{2}{|c|}{ Agree } & \multicolumn{2}{|c|}{$\begin{array}{c}\text { Uncertai } \\
n\end{array}$} & \multicolumn{2}{|c|}{ Disagree } & \multicolumn{2}{|c|}{ Agree } & \multicolumn{2}{|c|}{ Uncertain } & \multicolumn{2}{|c|}{ Disagree } & & \\
\hline & No & $\%$ & No & $\%$ & No & $\%$ & No & $\%$ & No & $\%$ & No & $\%$ & & \\
\hline $\begin{array}{l}\text { Organizationa } \\
1 \text { factors }\end{array}$ & 42 & 84 & 0 & 0 & 8 & 16 & 110 & 100 & 0 & 0 & 0 & 0 & $18.5^{\circ}$ & $\begin{array}{c}0.001 \\
* * \\
\end{array}$ \\
\hline $\begin{array}{l}\text { Personal } \\
\text { factors }\end{array}$ & 38 & 76 & 0 & 0 & 12 & 24 & 82 & 74.5 & 0 & 0 & 28 & 25.5 & 0.03 & 0.844 \\
\hline $\begin{array}{l}\text { Educational } \\
\text { factors }\end{array}$ & 50 & 100 & 0 & 0 & 0 & 0 & 106 & 96.4 & 0 & 0 & 4 & 3.6 & 1.86 & 0.172 \\
\hline $\begin{array}{l}\text { Social } \\
\text { factors }\end{array}$ & 45 & 90 & 0 & 0 & 5 & 10 & 110 & 100 & 0 & 0 & 0 & 0 & 11.3 & $\begin{array}{c}0.001 \\
* *\end{array}$ \\
\hline Total & 43 & 86 & 0 & 0 & 7 & 14 & 108 & 98.2 & 0 & 0 & 2 & 1.8 & 9.60 & $\begin{array}{c}0.002 \\
*\end{array}$ \\
\hline
\end{tabular}


Table (3) Best fitting multiple linear regression model of the effect nursing shortage of nurses work.

\begin{tabular}{|c|c|c|c|c|c|}
\hline Shortage & Beta & t & \multirow{2}{*}{ P value } & \multicolumn{2}{|c|}{ 95\%CI } \\
\cline { 5 - 6 } & & & & Lower & Upper \\
\hline Nurses work & 0.126 & 13.1 & $0.001^{* *}$ & 12.9 & 17.6 \\
\hline
\end{tabular}

$(*)$ statistically significant at $\mathrm{p}<0.05(* *)$ highly statistically significant at $\mathrm{p}<0.001$

\section{IV- Strategies to manage nursing shortage problem}

Table (4): Agreement of the studied sample on strategy to manage nursing shortage by hospital.no (160)

\begin{tabular}{|c|c|c|c|c|c|c|c|c|c|c|c|c|c|c|}
\hline \multirow{3}{*}{ Hospital } & \multicolumn{6}{|c|}{ Head nurses $(\mathrm{N}=50)$} & \multicolumn{6}{|c|}{ Nurses $(\mathbf{N}=110)$} & \multirow{3}{*}{$\chi^{2}$} & \multirow{3}{*}{$\begin{array}{c}\mathbf{P} \\
\text { value }\end{array}$} \\
\hline & \multicolumn{2}{|c|}{ Agree } & \multicolumn{2}{|c|}{ Uncertain } & \multicolumn{2}{|c|}{ Disagree } & \multicolumn{2}{|c|}{ Agree } & \multicolumn{2}{|c|}{ Uncertain } & \multicolumn{2}{|c|}{ Disagree } & & \\
\hline & No. & $\%$ & No. & $\%$ & No. & $\%$ & No. & $\%$ & No. & $\%$ & No. & $\%$ & & \\
\hline $\begin{array}{l}\text { Expression of } \\
\text { ideas freely }\end{array}$ & 49 & 98 & 0 & 0 & 1 & 2 & 105 & 95.5 & 4 & 3.6 & 1 & 0.9 & 2.16 & 0.338 \\
\hline $\begin{array}{l}\text { Plan for nurse } \\
\text { distribution } \\
\text { equally }\end{array}$ & 47 & 94 & 1 & 2 & 2 & 4 & 108 & 98.2 & 2 & 1.8 & 0 & 0 & 4.46 & 0.107 \\
\hline $\begin{array}{l}\text { Opportunities } \\
\text { for continuing } \\
\text { education }\end{array}$ & 50 & 100 & 0 & 0 & 0 & 0 & 107 & 97.3 & 3 & 2.7 & 0 & 0 & 3.56 & 0.168 \\
\hline $\begin{array}{l}\text { Provide } \\
\text { upgrade sin }\end{array}$ & 47 & 94 & 0 & 0 & 3 & 6 & 110 & 100 & 0 & 0 & 0 & 0 & 6.72 & 0.010 \\
\hline $\begin{array}{l}\text { Infection } \\
\text { control strategy } \\
\text { guideline }\end{array}$ & 50 & 100 & 0 & 0 & 0 & 0 & 108 & 98.2 & 2 & 1.8 & 0 & 0 & 0.921 & 0.337 \\
\hline $\begin{array}{l}\text { Improve } \\
\text { working } \\
\text { environment }\end{array}$ & 50 & 100 & 0 & 0 & 0 & 0 & 110 & 100 & 0 & 0 & 0 & 0 & - & - \\
\hline $\begin{array}{l}\text { Improve wages } \\
\text { and benefit }\end{array}$ & 50 & 100 & 0 & 0 & 0 & 0 & 110 & 100 & 0 & 0 & 0 & 0 & - & - \\
\hline $\begin{array}{l}\text { Availability of } \\
\text { entirement }\end{array}$ & 49 & 98 & 0 & 0 & 1 & 2 & 101 & 91.8 & 0 & 0 & 9 & 8.2 & 2.24 & 0.134 \\
\hline $\begin{array}{l}\text { Protective } \\
\text { measures }\end{array}$ & 50 & 100 & 0 & 0 & 0 & 0 & 110 & 100 & 0 & 0 & 0 & 0 & - & - \\
\hline $\begin{array}{l}\text { Provide } \\
\text { equipment and } \\
\text { medical } \\
\text { supplies }\end{array}$ & 45 & 90 & 4 & 8 & 1 & 2 & 108 & 98.2 & 2 & 1.8 & 0 & 0 & 5.91 & 0.051 \\
\hline Transport & 50 & 100 & 0 & 0 & 0 & 0 & 104 & 94.5 & 6 & 5.5 & 0 & 0 & 2.83 & 0.092 \\
\hline Good meals & 49 & 98 & 0 & 0 & 1 & 2 & 110 & 100 & 0 & 0 & 0 & 0 & 2.21 & 0.137 \\
\hline Child nursery & 47 & 94 & 2 & 4 & 1 & 2 & 110 & 100 & 0 & 0 & 0 & 0 & 6.72 & 0.035 \\
\hline $\begin{array}{l}\text { Treatment of } \\
\text { nurse and their } \\
\text { family free }\end{array}$ & 48 & 96 & 0 & 0 & 2 & 4 & 110 & 100 & 0 & 0 & 0 & 0 & 4.45 & 0.0354 \\
\hline
\end{tabular}


Discussion:

The present study aimed to identify nursing personal perception toward nursing shortage factors and it is effect on their work. That can be achieved through; identifying the nursing shortages factors, determining the effect nursing shortages factors on nurses work and determining strategies for solving nursing shortages at Benha University hospital.

There was result of the present study covered five main areas; firstly sociodemographic characteristics of studied group, secondly; factors affecting nursing shortage, thirdly; effect of nursing shortage on nurses work, fourthly; the strategies to manage the problem of nursing shortage, fifthly correlation between factors of nursing shortage.

\section{I: Socio-demographic characteristics of the study subjects:}

In relation to socio-demographic characteristics of the studied group,the result of the present study revealed that, the most of the studied group were female and married, the all head nurses group had bachelor degree, more than two third of them had more than fifteen years of experience and they aged from thirty to forty years. While the most staff nurse group aged from thirty to forty years, had diploma in nursing and more than one third them had of fifteen years of experience.

In the same line Ageiz, (2012) conducted study about the health care working conditions that affect patient safety as perceived by the nursing staff, who found that the majority of nurses had nursing diploma degree. Also this study was matched with Abd- Allah, (2010) conducted study about the shortage of clinical nurse specialist at intensive care units, who found that the majority of nurses had more than ten years of experience. The present study is incongruent with Gab-Allah, (2012) who conducted study about the relationship between nursing shortage and patient outcome, who found that the majority of nurses had five to ten years of experience.

\section{II-Factors affecting nursing shortage:-}

Regarding to the total nursing shortage factors, the result of the present study revealed that there was a highly statistical significant difference between studied group regarding their agreement about total organizational factors, this may be due to inadequate salary and benefits, increase number of patient, unequal distribution of night and evening, lack of nurses involvement in decision making.

Also the result of present study revealed that there was a highly statistical significant difference between studied group regarding their agreement about total social factors. This may be due to society sees nursing as career for profit only and bad image of nursing profession. Onthe other hand the result of the present study there was a statistical significant difference between studied group regarding their agreement about total nursing shortage factors. This may be due to all nursing shortage factors (organizational, personal, educational and social factors) can lead to nursing shortage.

This result was supported with Goodin, (2008) who found that the main factors contribute to causing shortage were related to poor public image, inadequate salary and benefits, unsafe work environment. The present study was matched with Buerhaus et al., (2007) conducted study about Impact of the nurse shortage on hospital patient care. They found that top reasons for nursing shortage were related to be inadequate salary and benefits, lack of nurses involvement in decision making, society sees nursing as career for profit only, undesirable hours. This was consistent with Erikson \&Svedlund, (2013) conducted study about struggling for confirmation- patient experiences of 
dissatisfaction with hospital care. They found that all respondent in their study have a negative image of nursing and inadequate salary and benefits.

Regarding to the best fitting multiple linear regression models explaining the effect of nursing shortage on nurse's work. The result of the present study revealed that there were significant predictors effect on nurses work.This may be due to increase work over time that causes communication problem with health team because too much responsibility that lead to poor health care quality for patient.

In the same line Aiken et al., (2011) conducted study hospital nurse staffing and patient mortality, nurse burnout, and job dissatisfaction. Who found that nurses high level of burnout and dissatisfaction intended to leave their jobs within a year. Also the result was matched with Buerhaus et al., (2007) they found that insufficient staffing raising the stress level of nurses, impacting job satisfaction and causing nurses to leave the nursing profession.

\section{Strategies to manage the problem of nursing shortage:}

Regarding tostrategy to manage the nursing shortage problem through hospitals. The result of the present study revealed thatall studied group agreement on all items; improve working environment, improve wages and benefit and infection control strategy guidelines. This may be due to all items of this strategy are important to attract and retain new and older nurses. Hospital services as child care service is important factor because the nurse reassured on her children at a safe place. Also transporting means are essential for nurses to safe time and help the nurse to attend at the exact time of work
This result was agreed with AbdAllah, (2010) who found the nursing shortage problem can be solved through improve working condition. Also the result was matched with Buerhaus et al., (2007) and Gab Allah, (2012). They found that the majority of nurses agreed on improve working environment is one of strategy to improve nursing shortage. Also the result of the present study was matched with Mitchell, Areeg\&Szabo, (2014) conducted study about work place violence among nurses. They found safe working environment are central to provide high quality health care.

\section{Conclusion}

The present study was conducted to identify nursing personnel perception toward nursing shortage factors and its effect on their work. The result showed that most studied sample agreed that the organizational, personal, educational and social factors are contributing to the nursing shortage. Most of them agreed work overload, inadequate salary and incentives, unsafe work environment, lack of educational program and society sees nursing as career for profit only are contributing to nursing shortage. Most of the studied sample agreed that the nursing shortage leads to increase job stressor, low level of productivity and inability to maintain patient safety. In addition the most study sample agreed on the strategies to manage the problem of nursing shortage that related to community outreach programs; improving nursing image, knowing written performance standard and guidelines, activating the role of the union to improve profession of nurse, honoring the ideal nurse and improve wages and benefits.

\section{Recommendations}

In the light of the findings obtained from the present study, the following recommendations are suggested: 


\section{At practical level:-}

Hospital administrators, accrediting agencies, and regulators should take action to ensure that an adequate nursing staff is available to protect patients and to improve the quality of care.

There should be a clear plan for nurses' distribution all over the country and at the hospital level to cover work needs and prevent workload.

Hospitals and health care agencies should work to improve the working environment and improve recruitment and retention of nurses.

Effective retention policies should be tailored to the nature and composition of the supply of nurses.

Hospital administrators, nurses, and media should work together to improve the image of nursing.

Overtime should be voluntary and its pay should be increased regularly.

Hospital administrators should be encourage of good nurses by honoring the ideal nurse.

The position for an assistant nurse (nurses' aids) should be developed. This can help to eliminate unimportant, repetitive, and routine tasks from professional nurses' practice.

\section{At educational level:-}

Conduct in-service education program for nursing to up date their knowledge.

Designing and implementing education training plan staff through continuous educations training center to decrease nursing shortage.

\section{At research level:-}

Conducting further studies on large probability sample to achieve generalizable results.

A comparative study between hospitals to identify adequately staffed to provide additional evidence of the relationship between nursing shortage and effect on their work.

Conduct a study to evaluate the effect of different strategies on nurse's performance.

\section{References:}

Abd Allah, S. (2010): Study the shortage of clinical nurse specialist in intensive care units. Master thesis, Faculty of Nursing, Tanta University, pp: 72-76.

GabAllah, A.(2012): Study the relationship between nurses shortage and patient outcome Menoufyia University. Master thesis, Faculty of Nursing,.Pp: 25-26

Buerhaus, P., Donelan, K., Beth, T., Ulrich Vorman, L., DesRoches, C., and Dittus, R. (2007): Impact of the nurse shortage on hospital patiewnt care. Comparative perspectives 26(3):853-862.

Goodin, H.J. (2008): Integrative literature reviews and meta-analyses the nursing shortage in the united states of america: an integrative review of the literature. Available on : http://www.blackwellsvnergv.com/doi. Retrieved at 4. March, 2016, 12:00pm.

Erikson, I.L. and Svedlund, M. (2013): Struggling for Confirmation Patients' Experiences of dissatisfaction with Hospita Journal Clinical Nurses, 16(3): 438-446.

Aiken L.H., Clarke S.P., Sloane D.M., Sochalski, A. and Sliber J. (2011): 
Hospital nurse staffing and patient mortality, nurse burnout and job dissatisfaction. Journal of Nursing, 52(4): 288-300.Zerwekh, J., Ashley and Garneau, (2015): Nursing to day transition and trends evolve, $8^{\text {th }} \mathrm{ed}$, Elsevier. Pp: 300-325.

Park, M., \& Jones, C. (2015): A retention strategy for newly graduated nurses. An integrative review of orientation programs. Journal for Nurses in Staff Development,26(4):142-149.

Kuhar, P. A., Miller, D., Spear, B. T., Ulreich, S. M., \&Mion, L. C. (2009): The meaningful retention strategy inventory: A targeted approach to implementing retention strategies. Journal of Nursing Administration,34(1):10-18.

Needleman, J. \&Beurau, P. (2009):Nursestaffing levels and the quality of care in hospitals. New England Journal of Medicine: 346 (22): p. 346, 1715-1722.

Ageiz, M. (2012): The health care working conditions that affect patient safety as perceived by the nursing staff. Master thesis, Faculty of nursing, Menoufyia University, pp 102-105.

Buerhaus, P., Auerbach, D., Staiger, D. (2009): Recent trends in the registered nurse labor market in the US: Short-run Swings on Top of Long-term Trends. Nursing Economics,25(2):59-66.

Diane, L.,Huber, Phd, RN, NEa. BC, FAAN. (2015): Leadership nursing care management professor college of nursing and college of public health. 5th ed., The University of lowa. Lowa city., PP 33

Rashdan, T. (2007): Implication for advancement of egyptian nursing: input equal output. White paper for Fulbright academy. Doha. Available on www. Fullbright Academy.org. Retrieved at 20.March, 2015,11:00pm.

Tomey, A. M. (2013): Guide to nursing management and leadership. $8^{\text {th }}$ ed. Canada: Mosby Elsevier, pp 386, 387, 390. 